Article

\title{
Dual Nanofibrous Bioactive Coatings on TiZr Implants
}

\author{
Mariana Prodana ${ }^{1}$, Claudiu-Eduard Nistor ${ }^{2}$, Andrei Bogdan Stoian ${ }^{1}\left(\mathbb{D}\right.$, Daniela Ionita ${ }^{1, *(\mathbb{D})}$ and \\ Cristian Burnei ${ }^{3}$ \\ 1 Department of General Chemistry, Faculty of Applied Chemistry and Materials Science, University \\ Politehnica of Bucharest, 313 Splaiul Independentei, 060042 Bucharest, Romania; \\ prodana_mariana@yahoo.com (M.P.); andreibstoian@yahoo.com (A.B.S.) \\ 2 Central Military University Emergency Hospital “Dr. Carol Davila”, Calea Plevnei Street, 134, \\ 010825 Bucharest, Romania; ncd58@yahoo.com \\ 3 Clinical Emergency Hospital, Calea Floreasca 8, 014461 Bucharest, Romania; burneicristian@yahoo.com \\ * Correspondence: daniela.ionita@upb.ro; Tel.: +40-21-402-3930
}

Received: 10 May 2020; Accepted: 27 May 2020; Published: 29 May 2020

check for updates

\begin{abstract}
The objective of this research was to obtain a dual coating with antimicrobial properties on TiZr implants. The metallic surfaces were modified with two biopolymers (poly(lactic acid) and polycaprolactone), the first deposited by dip coating and the second by electrospinning, in order to create a nanofibers type of coating with antibacterial and bioactive effect. The surface characteristics of the obtained bioactive coatings were evaluated by Fourier Transformed Infrared Spectroscopy, by scanning electron microscopy and by contact angle measurements. The electrochemical characterization of the coatings was performed in simulated body fluid. The metallic ion release from the coated implant materials was measured by inductively coupled plasma mass spectrometry. The in vitro antimicrobial properties of the coatings were studied using agar disc diffusion method and percentage inhibition of growth method for two bacterial strains-S. aureus and E. coli. The presence of silver nanoparticles presented high inhibition zone against gram negative bacteria like E. coli. Cell viability of MC3T3-E1 osteoblasts and cytoskeleton morphology, were tested in vitro for the biological evaluation. The results on in vitro cell response indicated good cell membrane integrity and viability for such nanofibrous bioactive coatings compared to the control substrate. These surface architectures design on implant materials holds promise for biomedical applications, presenting good antimicrobial properties and promote cell adhesion and proliferation.
\end{abstract}

Keywords: TiZr implants; surface properties; ion release; biological properties

\section{Introduction}

Titanium (Ti) and its alloys as dental and orthopaedic implants were the subject of many scientific investigations regarding the corrosion stability [1-3] or biological studies [4,5] due to their good biocompatibility and robust mechanical properties. Due to the oxide passive layer formed in reaction with oxygen in the air, Ti and its alloys present high corrosion resistance and good biocompatibility [6-8]. The new alloys with zirconium ( $\mathrm{Zr}$ ) [9] are considered safe and nonallergenic due to their corrosion resistance and good compatibility with tissues, having also high mechanical resistance [10]. Zr has demonstrated good mechanical strength, high corrosion resistance and biocompatibility. Zr is an isomorphic element which is soluble in Ti forming two phases ( $\alpha$ and $\beta$ ) [11]. Incorporation of $\mathrm{Zr}$ was used to improve the biocompatibility of Ti alloys [12].

Despite the wide use and proven efficiency of $\mathrm{Ti}$ and $\mathrm{TiZr}$ implants, some patients can develop adverse reactions to metals, which can lead to inflammatory processes and even implant rejection [13]. 
To overcome these issues, researchers focused on finding non-metallic materials suitable for implants. One of these materials is zirconia $\left(\mathrm{ZrO}_{2}\right)$ which has excellent biocompatibility, low bacteria adherence and high resistance. However, due to the chemical surface properties of surfaces $\mathrm{ZrO}_{2}$ cannot be easily nanotextured as Ti or TiZr. Thus, $\mathrm{ZrO}_{2}$ surfaces are usually modified by coatings or sandblasting which produce random structures. High quality controlled microstructures on $\mathrm{ZrO}_{2}$ have been recently obtained by ultra-fast laser ablation. The modified $\mathrm{ZrO}_{2}$ surfaces had good osteointegration, similar to Ti implants [14-16].

Antibacterial activity is the precondition criteria for an implant material because microbial contaminations are foremost cause of concern during treatment. Although Ti alloys, both coated and uncoated, have numerous remarkable properties, the development of bacterial infections on Ti implants can lead to implant failure but also have long-term deleterious side effects. Roughness of the material is one important factor for bacterial adhesion, a higher roughness promoting bacterial adhesion and the formation of biofilms, which offers bacteria resistance to antimicrobial agents [17].

Silver (Ag) has been documented as being an excellent antibacterial agent. Although the action involved in the antibacterial efficiency of Ag is not fully understood, three mechanisms were proposed-puncturing and destruction of bacterial cell walls [18], inhibition or disruption of metabolical pathways resulting in reactive oxygen species [19] or disruption of DNA replication cycles [20].

The use Ag nanoparticles (Ag-NPs) dispersed in polymer matrices permits the development of versatile antibacterial materials, exploiting the high surface to volume ratio of the Ag nanoparticles and the versatility of the polymers $[21,22]$.

Studies have been performed showing ways to protect patients from the developing of inflammatory response from Ti implants using coatings with hydroxyapatite (HA) and/or polymers [23,24].

Polycaprolactone (PCL) and Poly(lactic acid) (PLA) are aliphatic polyesters which are both biocompatible and biodegradable. PLA is more brittle, has lower elasticity, lower flexibility and degrades faster than PCL. PCL is more thermally stable than PLA and has low glass transition and melting temperatures. However, PCL has a low surface energy, decreasing cell adhesion on the surface. When PCL is blended with PLA, the limitations of both polymers can be overcome. The possibility of the application of these two polymers as bone graft scaffolds and biomaterials is growing since they complement each other in their physical properties and biodegradability [25].

Electrospun PLA/PCL blends have been used as scaffolds for tissue regeneration [26,27]. However, even these PLA/PCL blend fibres show smooth surface structure, the phase separation between PCL and PLA are present inside the fibres, because the two components are thermodynamically immiscible [27]. Increase of the adhesion strength to the implant is done by PLA film deposition known due to its good mechanical properties [28]. The deposition of PCL by electrospinning over the PLA film was employed in our work in order to increase the external coating area, that is, the large surface to volume ratio of the nanofibers providing more available space for the attachment of cells on the implant. Because of the hydrophobic nature of these polymers that can restrict cell growth, efforts have been made to improve their surface properties by different methods, one of which is to coat the electrospun surface with a layer of hydroxyapatite [26].

Sodium hydroxide $(\mathrm{NaOH})$ treatment was used for activating the hydrophobic polymer to enhance the wettability. When immersed in $\mathrm{NaOH}$ solution, the ester linkages along the polymer backbone break by random chemical scission, which leads to hydroxyl and carboxylic acid groups being exposed on the polymer surface $[29,30]$. Hydrophilicity is subsequently improved, as these groups are freely available to hydrogen bond with water molecules because of their slightly electronegative effects and less steric hindrance [30].

The aim of this study was to obtain a material based on TiZr with modified surface, with improved cell adhesion and proliferation that can develop new strategies for bone scaffolds and tissue engineering. Based on PLA interaction with metal implants [31] as well as PCL proven quality for better accommodation of the implant [32] we hypothesize that the combined PLA-PCL dual coating 
could enhance the implant accommodation. Furthermore, Ag-NPs should help the PLA-PCL dual coating in increasing its antibacterial activity [22].

This work studies the surface properties of PLA and PCL-PLA bioactive coatings deposited on TiZr. The porous PLA was chosen to improve the polymer adhesion to the TiZr substrate and to enhance the corrosion stability of the implant material. PCL was deposited as nanofibers by electrospinning, giving an enlarged total surface available for cell adhesion. The dual coating treated with Ag-NPs on TiZr implants creates an antibacterial effect. The surface characteristics of the bioactive coatings were evaluated by several techniques while the electrochemical characterization of the coating was studied in simulated body fluid. The metallic ion release from coated metallic implants was measured by inductively coupled plasma mass spectrometry (ICP-MS). In vitro antimicrobial properties for the coatings of the samples were studied using agar disc diffusion method and percentage inhibition of growth method for two bacterial strains-S. aureus and E. coli. The results on in vitro cell response indicated good cell membrane integrity and viability for such nanofibrous bioactive coatings compared to the control substrate, holding a great promise for biomedical applications.

\section{Materials and Methods}

\subsection{Pre-Treatment of the Samples}

The TiZr samples have 50 at.\% Zr and 50 at.\% Ti and were obtained from ATI Wah Chang Co. (Albany, OR, USA). The TiZr samples $(20 \mathrm{~mm} \times 20 \mathrm{~mm} \times 2 \mathrm{~mm})$ were first mechanically polished with a Buehler Beta equipment (ATM GmbH -Mammelzen, Germany) using $\mathrm{SiC}$ paper of increasing grits from P800 to P2400, then washed in an ultrasonic bath with deionized water and acetone $10 \mathrm{~min}$ each, etched for $1.5 \mathrm{~h}$ with a $3: 7$ solution of $30 \mathrm{wt} . \% \mathrm{H}_{2} \mathrm{O}_{2}: 98 \mathrm{wt} . \% \mathrm{H}_{2} \mathrm{SO}_{4}$, washed again with deionized water and dried at room temperature, in order to produce oxides and increase the roughness of the substrates for a better adhesion of the biopolymers on the substrate.

\subsection{Preparation of PLA/PCL Coatings}

TiZr/PLA samples were obtained by dip-coating method with a KSV Nima interface unit from Biolin Scientific (Espoo, Finland). In the first step, 90 mg PLA (Sigma-Aldrich, Saint Louis, MO, USA) were dissolved in $0.6 \mathrm{~mL}$ chloroform at room temperature. The pre-treated TiZr samples were dipped into the PLA solution for $30 \mathrm{~s}$. The dip coating instrument removed the sample vertically at constant speed of $2 \mathrm{~mm} / \mathrm{s}$.

A PCL solution was prepared using $15 \mathrm{wt} . \%$ poly(E-caprolactone) (Sigma-Aldrich) and acetone as the solvent. In this solution $5 \mathrm{wt}$.\% (relative to PCL) of silver nitrate were added dispersed in isopropanol. The mixture was ultrasonicated for $1 \mathrm{~h}$ under steering with a speed of $500 \mathrm{rpm}$ at the room temperature. After the ultrasonication, the mixture was exposed to $254 \mathrm{~nm}$ ultraviolet light from a Vilber VL-215.LC UV lamp (Vilber, Collégien, France) for $24 \mathrm{~h}$ to reduce the $\mathrm{Ag}^{+}$to $\mathrm{Ag}$ nanoparticles (NPs) [33]. Then, the PCL containing silver nanoparticles was deposited on the semi-dried PLA coating layer by electrospinning, using an in-house built equipment comprised of a high-voltage supply (ER series, Glassman High Voltage Inc. - High Bridge, NJ, USA), a syringe pump (KDS Legato 200, KDS Scientific - Holliston, MA, USA) and a flat electrically grounded Cu collector plate. The electrospinning parameters were $+20 \mathrm{kV}$ applied voltage, a tip-to-collector distance of $15 \mathrm{~cm}$ and a solution-feeding rate of $0.25 \mathrm{~mL} / \mathrm{h}$. After electrospinning, the TiZr/PLA-PCL+Ag-NPs specimens were dried in a vacuum oven at $37^{\circ} \mathrm{C}$ for $12 \mathrm{~h}$.

After preparation of the dual PLA/PCL+Ag-NPs coating on TiZr substrates, surface hydrolysis treatment was performed in order to modify the surface and introduce functionality of the samples. For this purpose, the samples were immersed in $1 \mathrm{M} \mathrm{NaOH}$ solutions for $2 \mathrm{~h}$ and they were washed repeatedly with distilled water and then dried at $37^{\circ} \mathrm{C}$ for $2 \mathrm{~h}$. 


\subsection{Surface Morphology}

The surfaces of the samples were studied using a scanning electron microscope (SEM). SEM characterization was performed with a Quanta 650 FEG from FEI from Thermo Fisher Scientific (Hillsboro, OR, USA) equipped with an Octane Silicon Drift Detector EDS sensor (EDAX, AMETEK, Inc., Mahwah, NJ, USA) microscope applying $2 \mathrm{kV}$ at a pressure of $2.2 \mathrm{mPa}$ using a working distance of $10 \mathrm{~mm}$.

\subsection{Fourier Transformed Infrared Spectroscopy (FT-IR)}

FT-IR spectra were recorded by using a Spectrum 100 Series FT-IR Spectrometer from Perkin Elmer (Waltham, MA, USA) in the range $4000-500 \mathrm{~cm}^{-1}$.

\subsection{Determination of Contact Angle}

The ability of a liquid to wet a flat solid was evaluated by measuring the contact angle $\theta$ that the liquid drop makes with the surface. The contact angle was determined with a Contact Meter CAM 100 equipment (KSV instruments -Espoo, Finland). The presented results are the average of three measurements for each sample and liquid.

\subsection{Adhesion Tests}

The film-substrate adhesion strength was evaluated using a PosiTest AT-M adhesion tester form DeFelsko (Ogdensburg, NY, USA) using $10 \mathrm{~mm}$ diameter aluminium dollies. The dollies were fixed on the samples with double adhesive tape and a force was applied until the polymer film detached from the TiZr substrates.

\subsection{Electrochemical Studies}

All electrochemical studies were carried out using an electrochemical cell with platinum as counter electrode, $\mathrm{Ag} / \mathrm{AgCl} 3 \mathrm{M}$ as reference electrode and coated and uncoated TiZr samples as working electrodes. Electrochemical tests were performed to study the stability and performance of the coatings on a Voltalab 40 potentiostat/ galvanostat equipment (Radiometer Analytical SAS, Lyon, France) with Voltamaster 4 software.

The test environment was simulated body fluid (SBF) solution with the composition shown in Table 1:

Table 1. SBF chemical composition (g/L).

\begin{tabular}{ccccccccc}
\hline $\mathbf{N a C l}$ & $\mathrm{KCl}$ & $\mathrm{CaCl}_{2}$ & $\mathrm{NaHCO}_{3}$ & $\mathrm{Na}_{2} \mathrm{HPO}_{2} \cdot \mathbf{2} \mathrm{H}_{2} \mathrm{O}$ & $\mathbf{M g C l}_{2} \cdot 6 \mathrm{H}_{2} \mathrm{O}$ & $\mathbf{K H}_{2} \mathbf{P O}_{4}$ & $\mathbf{M g S O}_{4} \cdot 7 \mathrm{H}_{2} \mathbf{O}$ & $\mathbf{C}_{6} \mathrm{H}_{12} \mathrm{O}_{6}$ \\
\hline 8 & 0.4 & 0.18 & 0.35 & 0.48 & 0.1 & 0.06 & 0.1 & 1 \\
\hline
\end{tabular}

\subsection{Inductively Coupled Plasma Mass Spectrometry (ICP-MS)}

The evolution of calcium and titanium ions release from coatings in time was measured with an Inductively Coupled Plasma Mass Spectrometry (ICP-MS) equipment Perkin Elmer ELAN DRC-e (Perkin Elmer, Waltham, MA, USA) in the working conditions presented elsewhere [34]. The equipment was working with liquid sample introduction by a micro-nebulizer and calibration was performed using aqueous multielement solutions for internal standardization.

\subsection{In vitro Mineralization}

The mineralization activity of the samples was tested by immersion in $10 \mathrm{~mL}$ of $5 \times$ SBF solution, which was refreshed every $24 \mathrm{~h}$ and kept at $37^{\circ} \mathrm{C}$. After 7 days, the samples were taken out, rinsed in deionized water and left to dry in atmosphere. After the immersion test, the surface morphology of the sample was characterized by SEM and EDS. 


\subsection{Antimicrobial Studies}

In vitro antimicrobial properties for the coatings of the samples were studied using agar disc diffusion method for two bacterial strains-S. aureus (ATCC 25923) and E. coli (ATCC 25922).

The preparation of the inoculi was performed from broth cultures (Tryptic soy broth with $0.6 \% \mathrm{~m} / \mathrm{v}$ yeast extract) incubated overnight at $37^{\circ} \mathrm{C}$. The diffusion technique used Muller-Hinton agar and was performed by coating the Petri dishes with a layer of agar $4 \mathrm{~mm}$ thick. The two strains of bacteria inoculua where then added in the Petri dishes and left $10 \mathrm{~min}$ in laminar airflow. Then, the clean and coated TiZr samples were placed in the dish at equal distances and incubated for $72 \mathrm{~h}$ at $37^{\circ} \mathrm{C}$. The width of the inhibition zone $(\mathrm{mm})$ was measured in order to evaluate the antibacterial effect of the TiZr samples on the selected strains.

In order to determine the percentage inhibition of growth for both bacterial strains (S. aureus and E. coli), the bacteria cultures were grown in tubes containing Luria-Bertani (LB) medium at $37^{\circ} \mathrm{C}$. The sterile medium of $50 \mathrm{~mL}$ was inoculated with $0.5 \mathrm{~mL}$ of suspension of bacterial cells. The samples were covered with $10 \mathrm{~mL}$ of culture. Incubation was performed in a Laboshake incubator (Gerhardt, Wiesbaden, Germany). After $18 \mathrm{~h}$ of incubation optical density was measured for four samples and control specimen (E. coli and S. Aureus culture without sample) using an UV-VIS Jenway Spectrophotometer (Cole-Pharmer, Stone, UK) at $600 \mathrm{~nm}$.

Knowing the optical densities (OD) the percentage inhibition of growth was determined, using Equation (1) [17]:

$$
I \%=\frac{\left(C_{18}-C_{0}\right)-\left(T_{18}-T_{0}\right)}{\left(C_{18}-C_{0}\right)} \cdot 100
$$

where $I \%$ is the percentage inhibition of growth, $C_{18}$ is the blank-compensated optical density at $600 \mathrm{~nm}\left(O D_{600}\right)$ of the positive control of the organism at $18 \mathrm{~h}, C_{0}$ is the blank-compensated $O D_{600}$ of the positive control of the organism at $0 \mathrm{~h}, T_{18}$ is the negative control-compensated $O D_{600}$ of the organism in the presence of test sample at $18 \mathrm{~h}$ and $T_{0}$ is the negative control-compensated $O D_{600}$ of the organism in the presence of test sample at $0 \mathrm{~h}$.

\subsection{Cell Viability Tests}

Preosteoblast cells (MC3T3-E1 - Merck KGaA - Darmstadt, Germany) were cultured in $\alpha$-MEM with added $10 \%$ foetal bovine serum, $100 \mathrm{U} / \mathrm{mL}$ penicillin and $100 \mu \mathrm{g} / \mathrm{mL}$ streptomycin in humidified atmosphere at $37^{\circ} \mathrm{C}$. Osteoblast cells were obtained in $\alpha$-MEM containing $50 \mathrm{mg} / \mathrm{L}$ ascorbic acid, $10 \mathrm{mM} \beta$-glycerophosphate and $50 \mathrm{ng} / \mathrm{mL}$ BMP2. All samples were sterilized with $2 \%$ penicillin and streptomycin solutions $1 \mathrm{~h}$ and incubated in growth medium for $3 \mathrm{~h}$ at $37^{\circ} \mathrm{C}$.

The cell morphology was visualized via fluorescence imaging using $20 \mu \mathrm{g} / \mathrm{mL}$ phalloidin conjugated with fluorescein isothiocyanate (FITC) (Sigma-Aldrich, St. Louis, MO, USA) to stain the actin and $2 \mu \mathrm{g} / \mathrm{mL} 4^{\prime}$,6-diamidino-2-phenylindole (DAPI) (Molecular Probes, Life Technologies, Eugene, OR, USA) to stain the nuclei of the cells. Micrographies were performed using an Olympus IX 71 fluorescence microscope (Olympus, Shinjuku, Japan).

The fluorescence was quantified using a fluorimeter (FP-750 Spectrofluorometer, Jasco, Hachiōji, Japan) with an excitation wavelength of $488 \mathrm{~nm}$ and emission wavelength of $515 \mathrm{~nm}$.

\section{Results and Discussion}

\subsection{Surface Morphology}

In Figure 1 are presented the surface morphology for all the samples. The TiZr sample (Figure 1a) exhibits oxide formations on the surface and small grooves resulted from the polishing procedure. On the sample surface covered with PLA (Figure 1b) there are present some pores with diameters between $0.5-1 \mu \mathrm{m}$. In Figure 1c, well defined PCL nanofibers with diameters between 150-600 nm appear parallel to the metal. In Figure 1d, a highly defined PCL nanofibers network is formed on the surface of the PLA layer deposited on the TiZr alloy. In this case the diameters of the nanofibers range 
between 180 and $700 \mathrm{~nm}$. The nodes where the nanofibers intersect having diameters in the range of $0.7-1.3 \mu \mathrm{m}$. In the inset of Figure 1d, at higher magnification, silver nanoparticles with diameters of $30-40 \mathrm{~nm}$ are visible on the PCL nanofibers, appearing as bright spots.
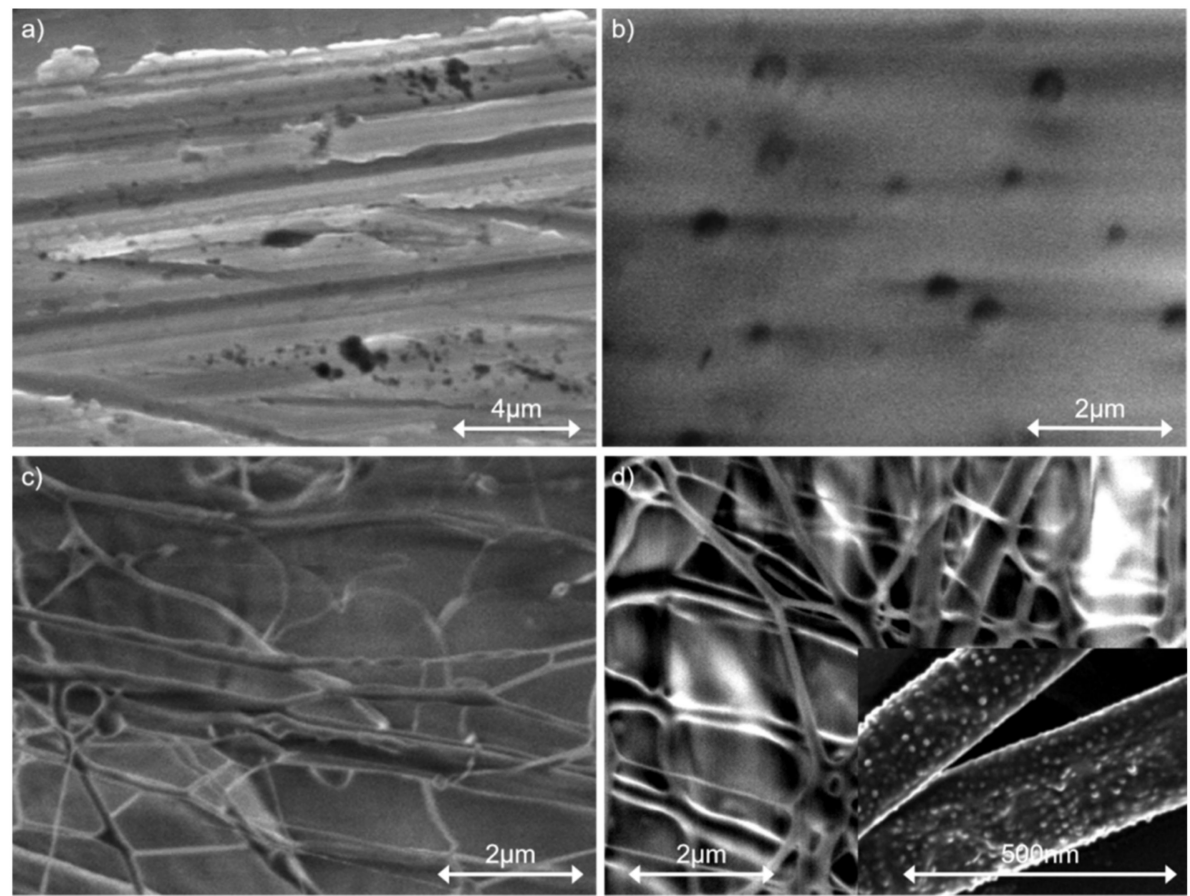

Figure 1. Morphologies of samples: (a) TiZr; (b) TiZr/PLA; (c) TiZr/PLA-PCL; (d) TiZr/PLA-PCL+Ag-NPs; inset - higher magnification of TiZr/PLA-PCL+Ag-NPs surface.

\subsection{FT-IR Analysis}

For the samples coated with PLA (Figure 2a) the peaks located at 2998 and $1751 \mathrm{~cm}^{-1}$ were attributed to the stretching of $\mathrm{CH}_{3}$ bonds and $\mathrm{C}=\mathrm{O}$ bonds respectively. For the samples coated only with PCL (Figure $2 b$ ) the peaks for the stretching vibration of $\mathrm{CH}_{3}$ and $\mathrm{C}=\mathrm{O}$ bonds was located at 2940 and $1720 \mathrm{~cm}^{-1}$. In the FT-IR spectra of TiZr coated with PLA/PCL+Ag-NPs the identified peaks at 2950 and $1750 \mathrm{~cm}^{-1}$ were attributed to the stretching and bending of $\mathrm{CH}_{3}$ bonds (Figure 2c). In the dual coating, PLA/PCL+Ag-NPs the C-O-C $\left(1794 \mathrm{~cm}^{-1}\right)$ and C-H $\left(2944 \mathrm{~cm}^{-1}\right)$ signals were shifted compared with pristine polymer. The shifting between the positions of the peaks are attributed to the stronger bonds formed between PLA and PCL [35] due probably to the polar interactions resulted from the solvent used in the PCL/PLA+Ag-NPs deposition. Alkaline hydrolysis will produce hydroxyl $(-\mathrm{OH})$ through cleaving the ester bond in polymeric coating. Theoretically, the appearance of $(-\mathrm{OH})$ groups was observed at wavenumbers ranging from 3300 to $3610 \mathrm{~cm}^{-1}$. 


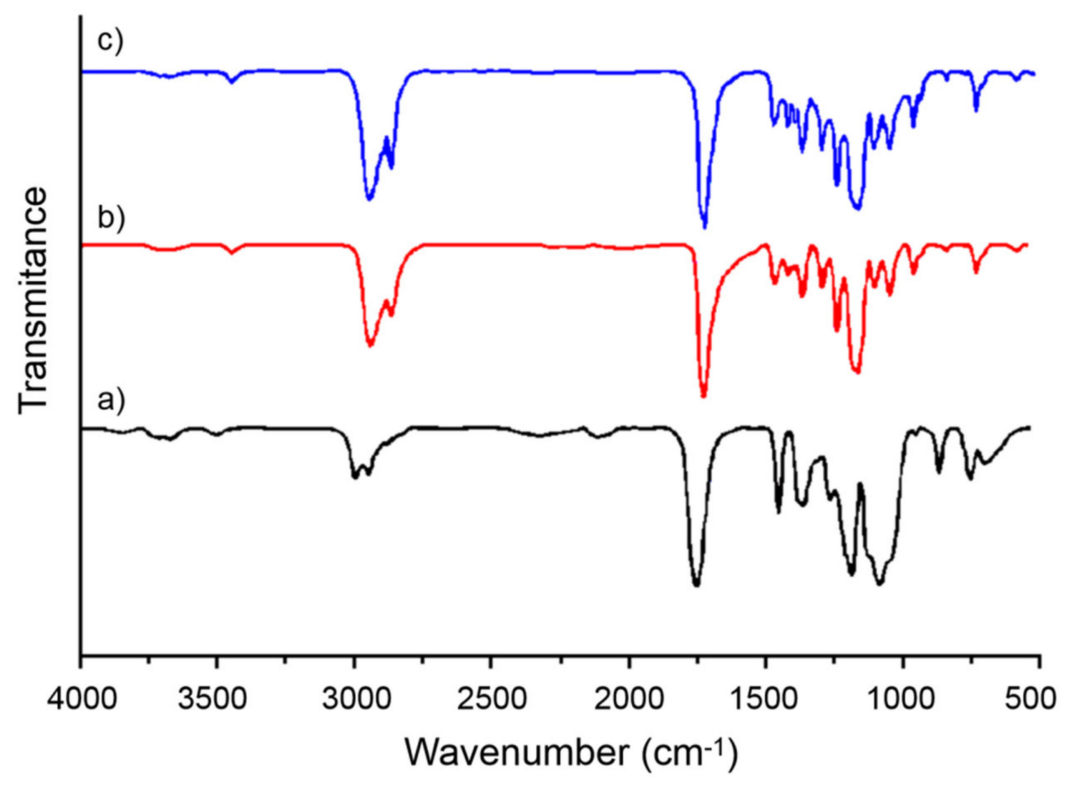

Figure 2. Fourier transform-infra red (FT-IR) spectra of samples: (a) TiZr/PLA; (b) TiZr/PCL; (c) TiZr/PLA-PCL+Ag-NPs.

\subsection{Contact Angle Measurements}

In order to characterize the surface of the samples we used liquid drop contact angle measurement. In our study, the Owen-Went model was used to calculate the polar and nonpolar components of surface. In this model, surface energy dissociates liquid ( $\mathrm{L}$, the media which is used to perform contact angle measurements) and solid (s, the surface under investigation) surface energy into its polar and nonpolar components, as shown in Equation (2):

$$
(1+\cos \theta) \gamma_{L}=2\left(\sqrt{\gamma_{L}^{d} \gamma_{S}^{d}}+\sqrt{\gamma_{L}^{p} \gamma_{S}^{p}}\right) .
$$

$\gamma_{\mathrm{L}}$ is the liquid surface free energy and $\gamma_{1}^{\mathrm{p}}$ and $\gamma_{1}^{\mathrm{d}}$ are the liquid surface energy polar and non-polar components, respectively. Similarly, $\gamma_{\mathrm{s}}$ is the solid surface free energy and $\gamma_{\mathrm{s}}{ }^{\mathrm{p}}$ and $\gamma_{\mathrm{s}}{ }^{\mathrm{d}}$ are the solid surface energy polar and non-polar components, respectively. $-\theta$ is the surface contact angle. The liquid polar and non-polar components of the liquids are listed in Table 2.

Table 2. Physical characteristics of liquids samples.

\begin{tabular}{cccc}
\hline Liquids & $\gamma_{1}\left(\mathrm{~mJ} / \mathrm{m}^{2}\right)$ & $\gamma_{1}{ }^{\mathrm{d}}\left(\mathrm{mJ} / \mathrm{m}^{2}\right)$ & $\gamma_{1}{ }^{\mathrm{p}}\left(\mathrm{mJ} / \mathrm{m}^{2}\right)$ \\
\hline Water & 72.6 & 21.6 & 51.0 \\
Diiodomethane & 50.8 & 48.5 & 2.3 \\
\hline
\end{tabular}

Wettability of the coatings surface and their surface free energy (SFE) were estimated using two different liquids, that is, water as a polar liquid and diiodomethane as a dispersive one. Our contact angle measurements showed that the coating of the TiZr surfaces confers a hydrophobic character of the surface as can be seen in Table 3 .

For surface energy, values higher than $30 \mathrm{mN} / \mathrm{m}$ indicate bioadhesion and a positive cell response [36].

The enrichment of our samples with Ag nanoparticles lead to the wettability decrease (increase of hydrophobic properties) and surface free energy decrease.

The surface properties of PLA are hydrophobic which is not favourable for cell growth on the surface [37]. PLA has no functional groups that can cleave to the active molecules. These considerations lead to limitations of the use of PLA in bone tissue engineering. 
Table 3. Angle values and surface energy for samples.

\begin{tabular}{|c|c|c|c|}
\hline \multirow{2}{*}{ Sample } & \multicolumn{2}{|c|}{ Contact Angle Values } & \multirow{2}{*}{ Surface Energy $\left(\mathrm{mJ} / \mathrm{m}^{2}\right)$} \\
\hline & Water & Diiodomethane & \\
\hline $\mathrm{TiZr}$ & $108.35 \pm 0.09$ & $37 \pm 0.16$ & $45.37 \pm 0.05$ \\
\hline TiZr/PLA & $131.92 \pm 0.12$ & $89.61 \pm 0.50$ & $15.09 \pm 0.09$ \\
\hline TiZr/PLA-PCL & $120.56 \pm 0.18$ & $67.33 \pm 0.96$ & $28.46 \pm 0.23$ \\
\hline TiZr/PLA-PCL+Ag-NPs & $124.28 \pm 0.06$ & $41.96 \pm 0.47$ & $51.97 \pm 0.15$ \\
\hline
\end{tabular}

In order to improve cell affinity to polymers and to promote bone growth, some surface modification techniques have been developed [38,39].

Among them, treatment with alkaline hydrolysis is a feasible and convenient method. After surface hydrolysis of the aliphatic polyester, the hydrophilic carboxyl and the hydroxyl can be produced by cleavage of the ester bonds.

After $\mathrm{NaOH}$ treatment, the contact angle values became significantly lower, from hydrophobic to hydrophilic (Table 4), which is beneficial for cell adhesion and increased biocompatibility.

Table 4. Contact angle values and surface energy for samples after $\mathrm{NaOH}$ treatment.

\begin{tabular}{|c|c|c|c|}
\hline \multirow{2}{*}{ Sample } & \multicolumn{2}{|c|}{ Contact Angle Values } & \multirow{2}{*}{ Surface Energy $\left(\mathrm{mJ} / \mathrm{m}^{2}\right)$} \\
\hline & Water & Diiodomethane & \\
\hline TiZr & $58.22 \pm 0.02$ & $67.7 \pm 2.18$ & $42.42 \pm 1.1$ \\
\hline TiZr/PLA & $55.55 \pm 0.06$ & $36.18 \pm 6.82$ & $50.86 \pm 0.8$ \\
\hline TiZr/PLA-PCL & $48.46 \pm 0.01$ & $32.32 \pm 2.75$ & $58.30 \pm 0.25$ \\
\hline TiZr/PLA-PCL+Ag-NPs & $52.45 \pm 0.19$ & $38.37 \pm 0.73$ & $53.7 \pm 0.05$ \\
\hline
\end{tabular}

\subsection{Adhesion Tests}

The adhesion strength values of the films on TiZr are presented in Table 5.

Table 5. Adhesion strengths of the coatings on TiZr.

\begin{tabular}{cc}
\hline Sample & Adhesion Strength (MPa) \\
\hline TiZr/PLA & $4.1 \pm 0.8$ \\
\hline TiZr/PCL & $1.7 \pm 0.3$ \\
\hline TiZr/PLA-PCL & $2.8 \pm 0.7$ \\
\hline TiZr/PLA-PCL+Ag-NPs & $2.7 \pm 0.5$ \\
\hline
\end{tabular}

In order to be able to draw a conclusion regarding the adhesion strength of the dual coating, it is necessary to refer to one-component coatings (TiZr/PLA and TiZr/PCL). For this purpose, a $\mathrm{TiZr} / \mathrm{PCL}$ sample was prepared. It was found that PCL has much lower adhesion strength than PLA. One possible explanation can be the molecular structure of PCL. Polymers with higher oxygen quantities in their structures can provide more electrostatic interactions on metallic surfaces [40]. PCL has less oxygen than PLA and exhibits lower adhesion to the surface. Poor adhesion between coatings and substrates can lead to the failing of the implant. However, PCL has better elastic properties than PLA. A compromise solution was chosen by reinforcing the PLA layer with networks composed of PCL nanofibers.

The results have shown that PLA-PCL dual layer tends to exhibit higher adhesion strengths than those of PCL layer on TiZr substrates. This can be attributed to the bonding interaction between PLA and PCL layers. The adhesion strength of PLA-PCL+Ag-NPs coating is not much different than the adhesion strength of the PLA-PCL coating. The Ag-NPs are present only on the PCL nanofibers. The adhesion strength represents the detachment of the coating from the TiZr substrate, thus the Ag-NPs have no real effect on adhesion at TiZr substrate. 


\subsection{Electrochemical Characterization}

The corrosion behaviour of the TiZr samples with and without coatings in SBF solutions are presented in Figure 3 . The corrosion potential $\left(E_{\text {corr }}\right)$, corrosion current density $\left(I_{\text {corr }}\right)$ and passive current densities ( $\left.i_{\text {pass }}\right)$ from the polarization curves are listed in Table 6. The corrosion resistance of the coated samples have been improved compared to that of the uncoated TiZr. The coating presence on TiZr surface led to the displacement of the corrosion potential towards more electropositive values than those of the uncoated samples. The highest corrosion resistance was recorded for TiZr/PLA-PCL. The presence of silver in the polymeric coating lead to insignificant changes in the corrosion parameters, not influencing the corrosion behaviour of the samples.

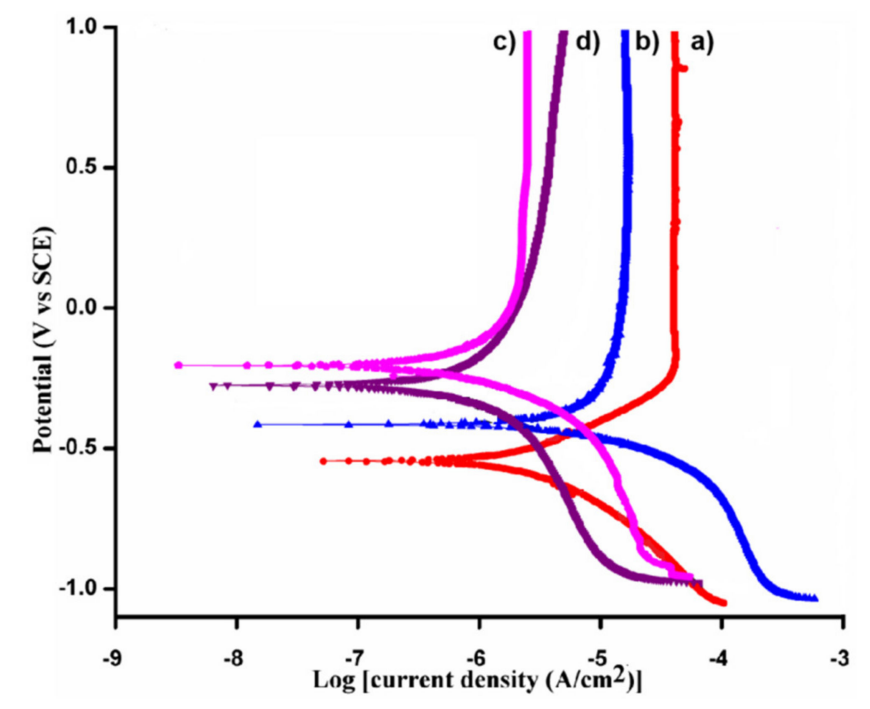

Figure 3. Polarization curves for (a) TiZr; (b) TiZr/PLA;.(c) TiZr/PLA-PCL; (d) TiZr/PLA-PCL+Ag-NPs in SBF solution.

Table 6. Electrochemical parameters for the analysed samples.

\begin{tabular}{|c|c|c|c|}
\hline Sample & $E_{\text {corr }}$ vs SCE (mV) & $i_{\text {corr }}\left(\mu \mathrm{A} / \mathrm{cm}^{2}\right)$ & $i_{\text {pass }}\left(\mu \mathrm{A} / \mathrm{cm}^{2}\right)$ \\
\hline $\mathrm{TiZr}$ & -552.8 & 68 & 885 \\
\hline TiZr/PLA & -420.8 & 35 & 205 \\
\hline TiZr/PLA-PCL & -203 & 4.6 & 40 \\
\hline TiZr/PLA-PCL+Ag-NPs & -275.6 & 6.5 & 28 \\
\hline
\end{tabular}

\subsection{ICP-MS Measurements}

The evaluation of Ag ions release was performed by ICP-MS technique by diffusion method. These studies were conducted in SBF. A specific volume $(2 \mathrm{~mL})$ of the sample was collected from the release medium at regular intervals, their ions release content being determined using ICP-MS to evaluate ions released from the sample containing silver nanoparticles.

ICP-MS data revealed that $3 \mathrm{~h}$ after immersion of TiZr/PLA-PCL+Ag-NPs system in the SBF solution, the concentration of $\mathrm{Ag}^{+}$ions was $0.18 \mathrm{ppm}$ and after 24 and $48 \mathrm{~h}$, it was 0.40 and $0.86 \mathrm{ppm}$, respectively. The release of Ag ions in SBF solution from the coatings was investigated during 10 days in order to evaluate the suitability of such coatings for use as antibacterial coatings for a long period. The concentration of released silver ions increased substantially in the first $48 \mathrm{~h}$. The release of silver ions starts to diminish after $66 \mathrm{~h}$, reaching a plateau after approximately $120 \mathrm{~h}$, hinting to a depletion of silver ions present on the sample. A logarithmic function $y=a-b \times \ln (x+c)$ was used to approximate the experimental data (and the fitted equations are shown in Figure 4). 


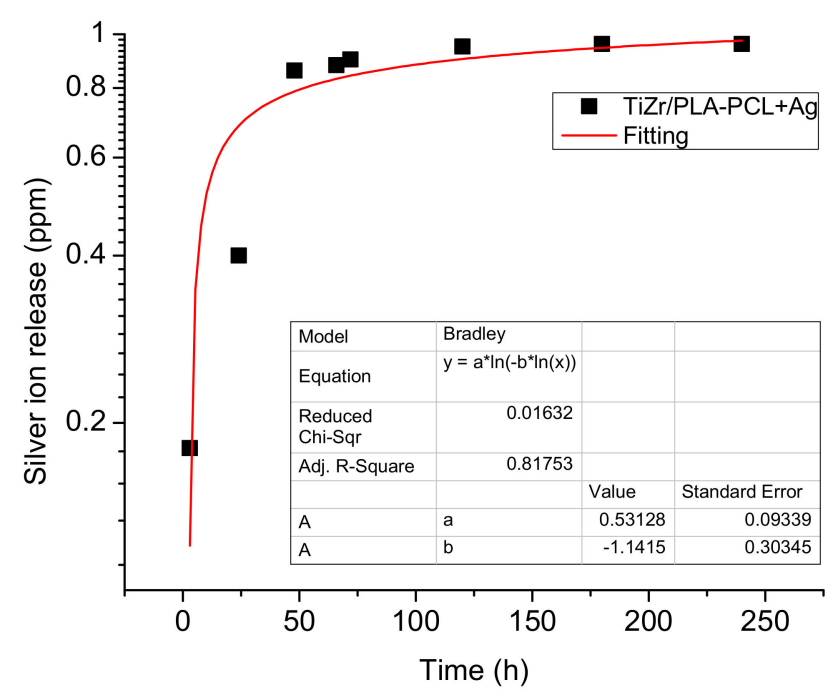

Figure 4. Ag ions release by Inductively Coupled Plasma Mass Spectrometry (ICP-MS) method.

The silver ions releasing in time from the sample TiZr/PLA-PCL+Ag-NPs is in agreement with the previous reports revealing a significant increase of the amount of silver ions at the initial stage [41] due to water diffusion on the surface, that is, easy water diffusion on the surface of the sample can result in a high rate release of silver ions at the initial stage.

According to Akhavan et al. [42], the time of $120 \mathrm{~h}$ for the sharp release of Ag ions represents a steady state, corresponding to a plateau behaviour (the time required for the amount of silver ions to reach approximately $80 \%$ of the total amount in the solution). After achieving the plateau shape the process of ions release is much slower.

The considerable reduction in the release rate of silver ions after reaching the saturation time, can be attributed to the slow diffusion of water in the sample.

Even so, during these 10 days of immersion tests, the silver concentration released coatings remained in the $\mathrm{ppb}$ range. As literature shows, even silver concentrations as low as $0.1 \mathrm{ppb}$ have a bactericidal effect in water $[43,44]$.

\subsection{In Vitro Mineralization}

Apatite formation is usually the first step involved in modifying an implant surface in order to improve the bone-bonding ability of materials.

After 7 days of immersion in $5 \times$ SBF the morphologies of samples are presented in Figure 5 .
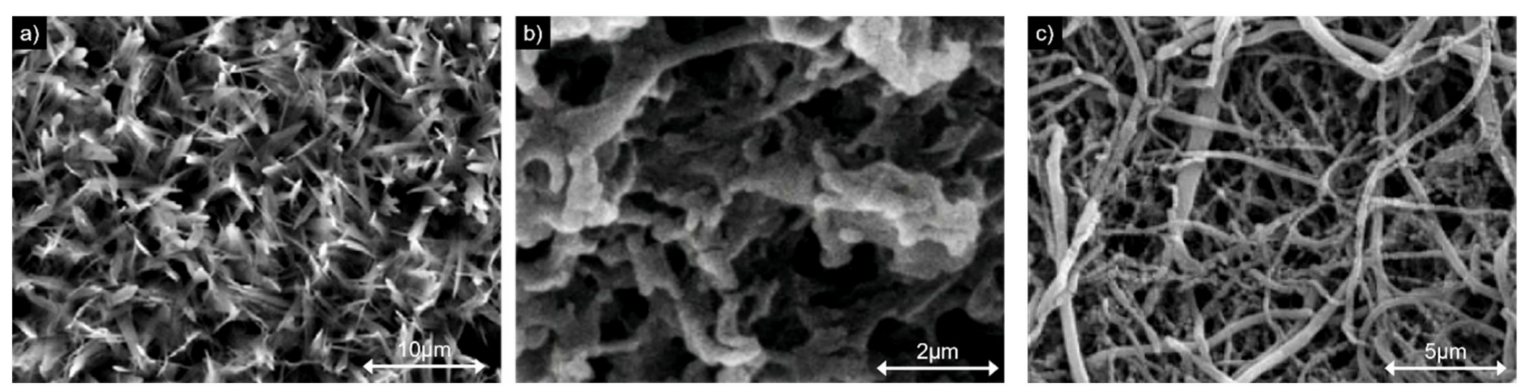

Figure 5. Morphologies of samples: (a) TiZr; (b) TiZr/PLA; (c) TiZr/PLA-PCL+Ag-NPs.

The TiZr sample (Figure 5a) was found covered in calcium phosphate (ortho-calcium phosphate). The shapes of the phosphate structures were flake-like and irregular. The sizes of the flakes vary around 5 and $10 \mu \mathrm{m}$.

Some differences were noticed for the TiZr/PLA sample (Figure 5b). The calcium phosphate formed porous structures around $2 \mu \mathrm{m}$. The dispersed pores were around $1 \mu \mathrm{m}$. 
The SEM micrographies for TiZr/PLA-PCL+Ag-NPs (Figure 5c) show the nanofibers surface almost completely covered with calcium phosphate. The immersion in SBF and covering with calcium phosphate led to the increase in the thickness of the fibres from 180-700 $\mathrm{nm}$ to $0.5-1.5 \mu \mathrm{m}$. Some fibres were found tangled, also some spherical calcium phosphate particles were found on some fibres. The morphology of TiZr /PLA-PCL sample was similar with TiZr /PLA-PCL+AgNP sample.

The rapid nucleation of calcium phosphate on coated TiZr plates was attributed to the general negative surface charge of the polymers, probably given after the alkali treatment. The negative charge favours the absorption of the positive calcium ions from the SBF [45].

EDS analysis were performed after the immersion in SBF in order to estimate the chemical composition of coatings. The results are shown in Table 7.

Table 7. Chemical composition of coatings.

\begin{tabular}{cccccccc}
\hline \multirow{2}{*}{ Sample } & \multicolumn{8}{c}{ Element (at.\%) } \\
& $\mathbf{C}$ & $\mathbf{O}$ & $\mathbf{C a}$ & $\mathbf{P}$ & $\mathbf{T i}$ & Zr & Ag \\
\hline TiZr & - & 47.92 & 18.34 & 14.99 & 10.25 & 8.50 & - \\
TiZr/PLA & 40.65 & 23.66 & 8.28 & 5.12 & 11.89 & 9.80 & - \\
TiZr/PLA-PCL+Ag-NPs & 45.55 & 25.79 & 5.62 & 3.46 & 10.10 & 8.70 & 0.78 \\
\hline
\end{tabular}

For the bare TiZr sample the ratio between $\mathrm{Ca}$ and $\mathrm{P}$ was 1.22 specific for ortho-calcium phosphate. The TiZr samples covered with PLA and PLA-PCL+Ag-NPs led to the formation of hydroxyapatite, in both cases the ratios between $\mathrm{Ca}$ and $\mathrm{P}$ were approximately 1.62 .

\subsection{Antibacterial Activity}

Figure 6a shows the antibacterial effect of all tested samples against S. aureus and E. coli. The measurements were repeated 5 times. The TiZr samples produced only a negligible area of bacterial inhibition. The coated TiZr samples produced clear regions of inhibition against both bacterial strains around the disc. The PLA coating on TiZr inhibited the growth of both S. aureus and E. coli. When the PCL nanofibers were deposited on top of the PLA layer, the antibacterial effect of the samples was reduced. This reduced effect can be attributed to the density of the PCL fibres that form a network through which the lactic acid from the polylactic acid must travel by diffusion processes. To overcome this effect, Ag nanoparticles were deposited on the PCL nanofibers, giving both coatings an antibacterial effect. The antibacterial activity observed for the PLA coatings can be attributed to the acidic $\mathrm{pH}$ in the culture medium, which is not favourable to bacteria growth, caused by residual lactic acid content from the samples $[46,47]$.
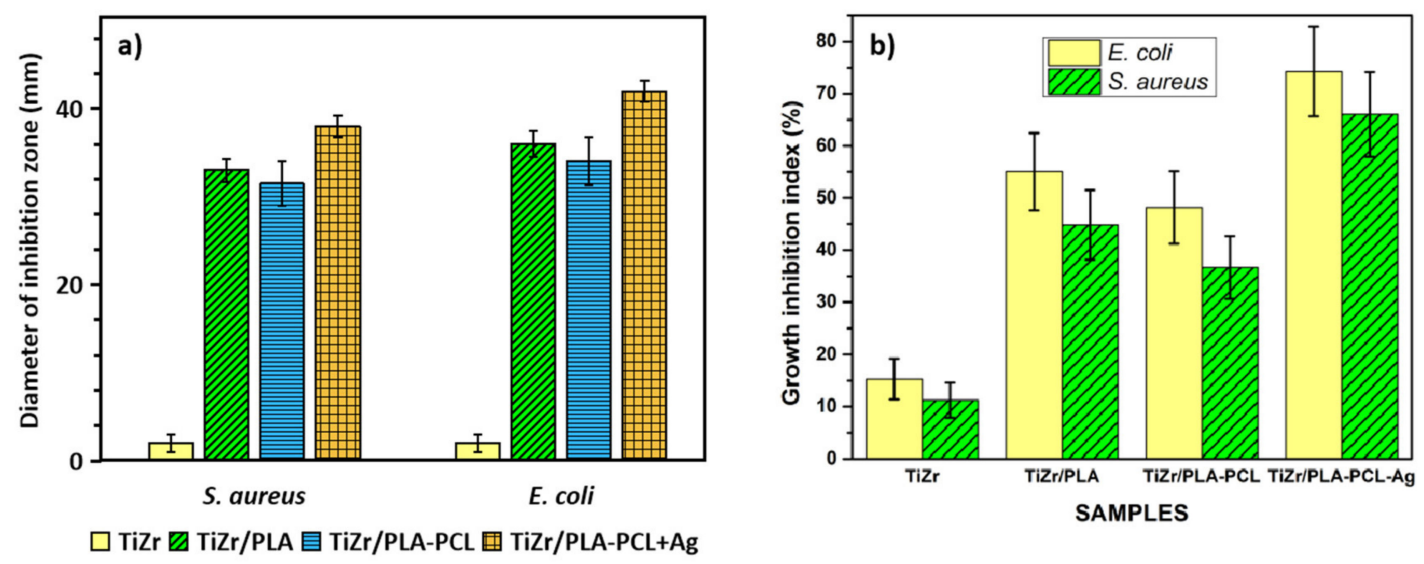

Figure 6. Schematic diagram of: (a) inhibition zone $(\mathrm{mm})$ and $(\mathbf{b})$ percentage inhibition of growth recorded for bare TiZr and coated samples. 
Figure $6 \mathrm{~b}$ shows the percentage inhibition of growth. For antibacterial activity evaluation were used following samples-TiZr, TiZr/PLA, TiZr/PLA-PCL and TiZr/PLA-PCL+Ag-NPs. We observed bacteria attached to a surface are able to duplicate, move and form colonies beyond the biofilm. The data presented are averaged over five replicates.

E. coli were $15.29 \%$ inhibited by the TiZr, $55.05 \%$ by the TiZr/PLA, $48.14 \%$ by TiZr/PLA-PCL and $74.27 \%$ inhibited by the TiZr/PLA-PCL+Ag-NPs. S.aureus were $11.24 \%$ inhibited by the TiZr, $44.82 \%$ by the TiZr/PLA, $36.64 \%$ by TiZr/PLA-PCL and $66.02 \%$ inhibited by the TiZr/PLA-PCL+Ag-NPs.

The silver released from the TiZr/PLA-PCL+Ag-NPs sample behaved the best in inhibiting growth of E. coli and S. aureus bacteria. Also, these results are in good agreement with the results obtain using agar disc diffusion method depicted in Figure 6a.

\subsection{Cell Viability Analysis}

The cell activity on the TiZr coated samples was measured at days 2 and 7 and compared with a control sample (bare TiZr). The results presented in Figure 7 show that all the coated samples have a good effect on cell proliferation, a slight decrease being present on the sample containing Ag-NPs. Consistent with these results, the cells adhered and spread out on the surface of all types of TiZr samples as can be seen in the fluorescence micrographies (Figure 8). It was observed that the cells maintained their normal aspect and proliferated on all the sample substrate. The modified samples produced no harm to the cells, suggesting that both the PLA and PCL/PLA coatings can promote cell growth and that the composites with Ag-NPs do not present high cytotoxicity.

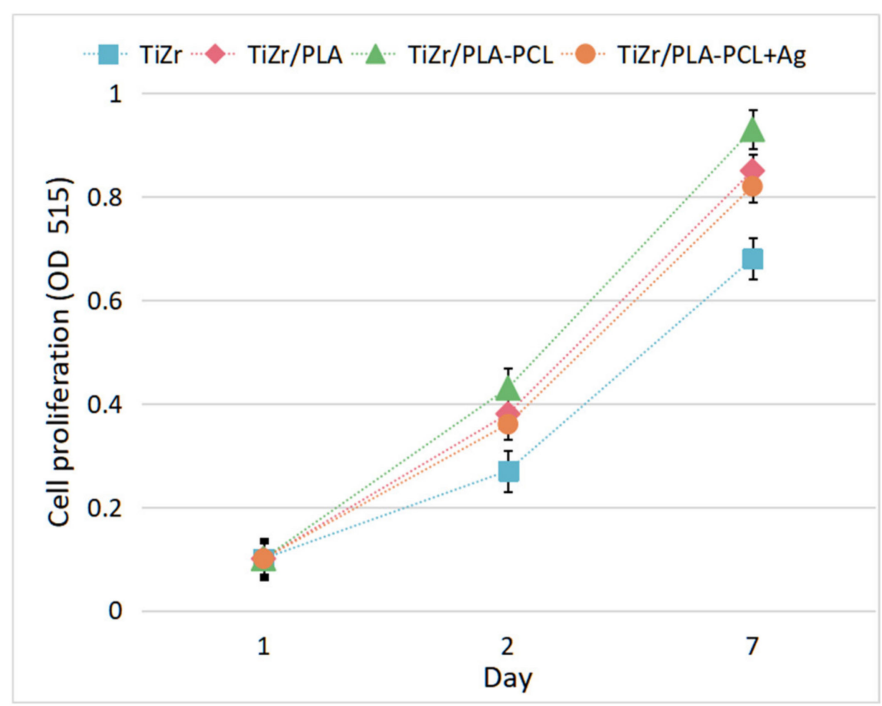

Figure 7. MC3T3-E1 cells proliferation on TiZr and coated samples. 

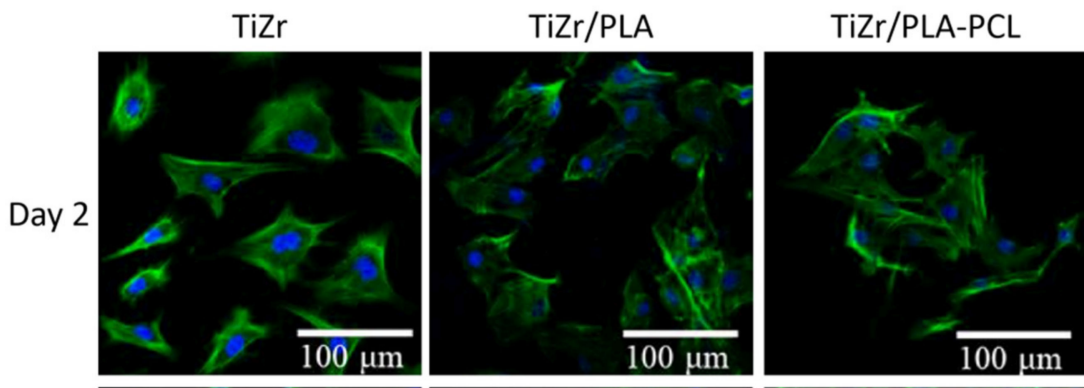

$\mathrm{TiZr} / \mathrm{PLA}-\mathrm{PCL}+\mathrm{Ag}$
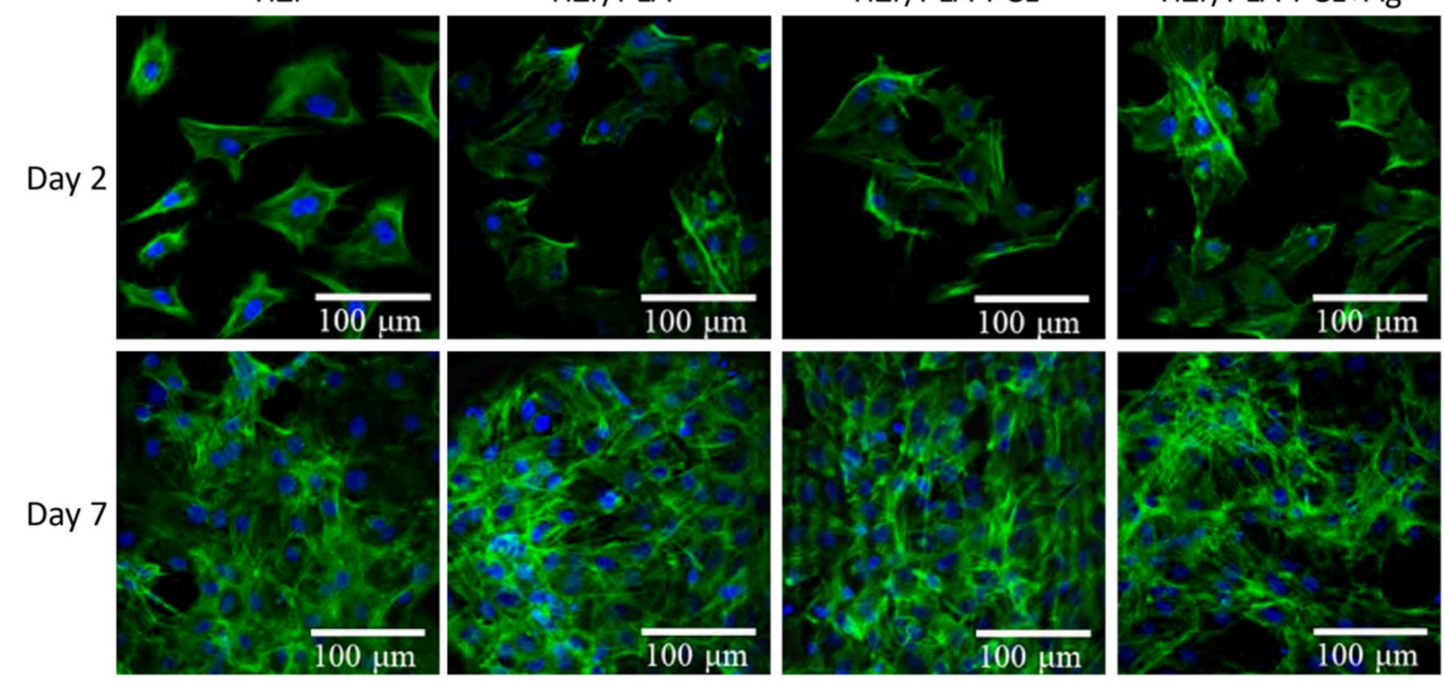

Figure 8. Effect of MC3T3-E1 cells adhesion and spreading (nuclei - blue colour, actin cytoskeleton green colour) on bare TiZr and coated TiZr samples after 2 and 7 days.

\section{Conclusions}

In this study we investigated the synthesis of a new dual material TiZr/PLA-PCL+Ag-NPs and we compared it with TiZr/PLA-PCL, TiZr/PLA obtained by electrodeposition and bare TiZr. The morphology of TiZr/PLA-PCL+Ag-NPs have showed that the sample was covered with a network of PCL nanofibers on which Ag-NPs were present. From the corrosion tests in SBF solution and ICP-MS investigations we observed that TiZr/PLA-PCL material has the best corrosion resistance and barrier properties for ions release. The silver nanoparticles addition presented high inhibition zone against gram negative bacteria like E. coli. However, even if the antimicrobial effect was well established in in-vitro experiments, the need for extensive in-vivo evaluation remains. From the clinical point of view the implants using TiZr/PLA-PCL+Ag-NPs coating will be safer and easier accommodated into the repaired bone structure. These results show that the composites using TiZr/PLA-PCL have promoted cell adhesion and proliferation that can develop new strategies for bone scaffolds. The hydrophilic character of the coating is a prognosis for good cell response and recommends such coating for new bioapplications.

Author Contributions: Conceptualization, D.I., methodology, M.P., D.I., and C.B.; software, A.B.S.; validation, C.-E.N., D.I., and M.P.; investigation, M.P., A.B.S., C.B., and C.-E.N.; data curation, D.I. and A.B.S.; writing-A.B.S. and M.P.; visualization - D.I., C.B., and C.-E.N.; supervision- D.I. All authors have read and agreed to the published version of the manuscript.

Funding: The work has been supported by the Operational Programme Human Capital of the Ministry of European Funds through the Financial Agreement 51668/09.07.2019, SMIS code 124705.

Acknowledgments: The SEM analyses on Quanta 650 FEG were possible due to European Regional Development Fund through Competitiveness Operational Program 2014-2020, Priority axis 1, Project No. P_36_611, MySMIS code 107066, Innovative Technologies for Materials Quality Assurance in Health, Energy and Environmental Center for Innovative Manufacturing Solutions of Smart Biomaterials and Biomedical Surfaces, INOVABIOMED.

Conflicts of Interest: The authors declare no conflict of interest.

\section{References}

1. Dilea, M.; Mazare, A.; Ionita, D.; Demetrescu, I. Comparison between corrosion behaviour of implant alloys Ti6Al7Nb and Ti6Al4Zr in artificial saliva. Mater. Corros. 2013, 64, 493-499. [CrossRef]

2. Chelariu, R.; Mareci, D.; Bolat, G.; Peptu, C.A.; Cailean, D. Electrochemical characterization of surface modification for Ti6Al7Nb implants with hydroxyapatite-zirconia nanoparticles synthesis by ultrasound irradiations. Mater. Corros. 2015, 66, 573-578. [CrossRef] 
3. Demetrescu, I.; Dumitriu, C.; Totea, G.; Nica, C.; Dinischiotu, A.; Ionita, D. Zwitterionic cysteine drug coating influence in functionalization of implantable ti50zr alloy for antibacterial, biocompatibility and stability properties. Pharmaceutics 2018, 10, 220-233. [CrossRef]

4. Swiatkowska, I.; Martin, N.; Hart, A.J. Blood titanium level as a biomarker of orthopaedic implant wear. J. Trace Elem. Med. Biol. 2019, 53, 120-128. [CrossRef]

5. Günay-Bulutsuz, A.; Berrak, O.; Yeprem, H.A.; Arisan, E.D.; Yurci, M.E. Biological responses of ultrafine grained pure titanium and their sand blasted surfaces. Mater. Sci. Eng. C 2018, 91, 382-388. [CrossRef]

6. Eliaz, N. Corrosion of Metallic Biomaterials: A Review. Materials 2019, 12, 407-498. [CrossRef]

7. Güleryüz, H.; Cimenoglu, H. Effect of thermal oxidation on corrosion and corrosion-wear behaviour of a Ti-6Al-4V alloy. Biomaterials 2004, 25, 3325-3333. [CrossRef]

8. Feng, B.; Chen, J.Y.; Qi, S.K.; He, L.; Zhao, J.Z.; Zhang, X.D. Characterization of surface oxide films on titanium and bioactivity. J. Mater. Sci. Mater. Med. 2002, 13, 457-464. [CrossRef]

9. Eisenbarth, E.; Velten, D.; Muller, M.; Thull, R.; Breme, J. Biocompatibility of $\beta$-stabilizing elements of titanium alloys. Biomaterials 2004, 25, 5705-5713. [CrossRef]

10. Grandin, H.M.; Berner, S.; Dard, M. A Review of Titanium Zirconium (TiZr) Alloys for Use in Endosseous Dental Implants. Materials 2012, 5, 1348-1360. [CrossRef]

11. Branzoi, I.V.; Iordoc, M.; Codescu, M. Electrochemical studies on the stability and corrosion resistance of new zirconium- based alloys for biomedical applications. Surf. Interface Anal. 2008, 40, 167-173. [CrossRef]

12. Ikarashi, Y.; Toyoda, K.; Kobayashi, E.; Doi, H.; Yoneyama, T.; Hamanaka, H.; Tsuchiya, T. Improved Biocompatibility of Titanium-Zirconium (Ti-Zr) Alloy: Tissue Reaction and Sensitization to Ti-Zr Alloy Compared with Pure Ti and Zr in Rat Implantation Study. Mater. Trans. 2005, 46, 2260-2267. [CrossRef]

13. Tibau, A.V.; Grube, B.D.; Velez, B.J.; Vega, V.M.; Mutter, J. Titanium exposure and human health. Oral. Sci. Int. 2019, 16, 15-24. [CrossRef]

14. Delgado-Ruíz, R.A.; Calvo-Guirado, J.L.; Moreno, P.; Guardia, J.; Gomez-Moreno, G.; Mate-Sánchez, J.E.; Ramirez-Fernández, P.; Chiva, F. Femtosecond laser microstructuring of zirconia dental implants. J. Biomed. Mater. Res. B Appl. Biomater. 2011, 96, 91-100. [CrossRef]

15. Delgado-Ruiz, R.A.; Calvo-Guirado, J.L.; Abboud, M.; Ramirez-Fernandez, M.P.; Maté-Sánchez de Val, J.E.; Negri, B.; Rothamel, D. Histologic and histomorphometric behavior of microgrooved zirconia dental implants with immediate loading. Clin. Implant. Dent. Relat. Res. 2014, 16, 856-872. [CrossRef]

16. Calvo-Guirado, J.L.; Aguilar-Salvatierra, A.; Delgado-Ruíz, R.A.; Negri, B.; Ramirez-Fernandez, M.P.; de Val Maté-Sánchez, J.E.; Gomez-Moreno, G.; Romanos, G.E. Histological and histomorphometric evaluation of zirconia dental implants modified by femtosecond laser versus titanium implants: An experimental study in fox hound dogs. Clin. Implant. Dent. Relat. Res. 2015, 17, 525-532. [CrossRef]

17. Grigorescu, S.; Ungureanu, C.; Kirchgeorg, R.; Schmuki, P.; Demetrescu, I. Various sized nanotubes on TiZr for antibacterial surfaces. Appl. Surf. Sci. 2013, 270, 190-196. [CrossRef]

18. Jung, W.K.; Koo, H.C.; Kim, K.W.; Shin, S.; Kim, S.H.; Park, Y.H. Antibacterial activity and mechanism of action of the silver ion in staphylococcus aureus and escherichia coli. Appl. Environ. Microbiol. 2008, 74, 2171-2178. [CrossRef]

19. Morones-Ramirez, J.R.; Winkler, J.A.; Spina, C.S.; Collins, J.J. Silver enhances antibiotic activity against gram-negative bacteria. Sci. Transl. Med. 2013, 5, 190ra181. [CrossRef]

20. Yakabe, Y.; Sano, T.; Ushio, H.; Yasunaga, T. Kinetic studies of the interaction between silver ion and deoxyribonucleic acid. Chem. Lett. 1980, 9, 373-376. [CrossRef]

21. Benhacine, F.; Hadj-Hamou, A.S.; Habi, A. Development of long-term antimicrobial poly ( $\varepsilon$-caprolactone)/silver exchanged montmorillonite nanocomposite films with silver ion release property for active packaging use. Polym. Bull. 2015, 73, 1207-1227. [CrossRef]

22. Turalija, M.; Bischof, S.; Budimir, A.; Gaan, S. Antimicrobial PLA films from environment friendly additives. Compos. B Eng. 2016, 102, 94-99. [CrossRef]

23. Kiran, A.S.K.; Kumar, T.S.S.; Perumal, G.; Sanghavi, R.; Doble, M.; Ramakrishna, S. Dual nanofibrous bioactive coating and antimicrobial surface treatment for infection resistant titanium implants. Prog. Org. Coat. 2018, 121, 112-119. [CrossRef]

24. Stoian, A.B.; Demetrescu, I.; Ionita, D. Nanotubes and nano pores with chitosan construct on TiZr serving as drug reservoir. Colloids Surf. B Biointerfaces 2020, 185, 110535. [CrossRef] 
25. Patrício, T.; Domingos, M.; Gloria, A.; D’Amora, U.; Coelho, J.F.; Bártolo, P.J. Fabrication and characterisation of PCL and PCL/PLA scaffolds for tissue engineering. Rapid Prototyp. J. 2014, 20, 145-156. [CrossRef]

26. Fang, R.; Zhang, E.; Xu, L.; Wei, S. Electrospun PCL/PLA/HA based nanofibers as scaffold for osteoblast-like cells. J. Nanosci. Nanotechnol. 2010, 10, 7747-7751. [CrossRef]

27. Lu, L.; Wu, D.; Zhang, M.; Zhou, W. Fabrication of Polylactide/Poly( $\varepsilon$ caprolactone) Blend Fibers by Electrospinning: Morphology and Orientation. Ind. Eng. Chem. Res. 2012, 51, 3682-3691. [CrossRef]

28. Hamad, K.; Kaseem, M.; Yang, H.W.; Deri, F.; Ko, Y.G. Properties and medical applications of polylactic acid: A review. Express Polym. Lett. 2015, 9, 435-455. [CrossRef]

29. Yoo, H.; Kim, T.; Park, T. Surface-functionalized electrospun nanofibers for tissue engineering and drug delivery. Adv. Drug Deliv. Rev. 2009, 61, 1033-1042. [CrossRef]

30. Cipitria, A.; Skelton, A.; Dargaville, T.; Dalton, P.; Hutmacher, D. Design, fabrication and characterization of PCL electrospun scaffolds-A review. J. Mater. Chem. 2011, 21, 9419-9453. [CrossRef]

31. Kulkarni, R.K.; Pani, K.C.; Neuman, C.; Leonard, F. Polylactic Acid for Surgical Implants. Arch. Surg. 1966, 93, 839-843. [CrossRef]

32. Sun, H.; Mei, L.; Song, C.; Cui, X.; Wang, P. The in vivo degradation, absorption and excretion of PCL-based implant. Biomaterials 2006, 27, 1735-1740. [CrossRef]

33. Zewde, B.; Ambaye, A.; Stubbs, J., III; Raghavan, D. A review of stabilized silver nanoparticles—Synthesis, biological properties, characterization, and potential areas of applications. JSM Nanotechnol. Nanomed. 2016, 4, 1043.

34. Prodana, M.; Murariu, A.; Meghea, A.; Demetrescu, I. Biomonitoring as assessment of human exposure to heavy metals. Speciation of $\mathrm{Hg}$ in fish food and impact on human health. Mater. Res. Innov. 2009, 13, 409-412. [CrossRef]

35. Dadras Chomachayi, M.; Jalali-arani, A.; Beltrán, F.R.; de la Orden, M.U.; Martínez Urreaga, J. Biodegradable Nanocomposites Developed from PLA/PCL Blends and Silk Fibroin Nanoparticles: Study on the Microstructure, Thermal Behavior, Crystallinity and Performance. J. Polym. Environ. 2020, 28, 1252-1264. [CrossRef]

36. Katsikogianni, M.; Missirlis, Y.F. Concise review of mechanisms of bacterial adhesion to biomaterials and of techniques used in estimating bacteria-material interactions. Eur. Cell Mater. 2004, 8, 37-57. [CrossRef]

37. Shi, X.; Jiang, J.; Sun, L.; Gan, Z. Hydrolysis and biomineralization of porous PLA microspheres and their influence on cell growth. Colloids Surf. B Biointerfaces 2011, 85, 73-80. [CrossRef]

38. Ghorbanpour, M. Amine accessibility and chemical stability of silver SPR chips silanised with APTES via vapour phase deposition method. J. Phys. Sci. 2016, 27, 39-51.

39. Araujo, J.V.; Martins, A.; Leonor, I.B.; Pinho, E.D.; Reis, R.L.; Neves, N.M. Surface controlled biomimetic coating ofpolycaprolactone nanofiber meshes to be used as bone extracellular matrix analogues. J. Biomater. Sci. Polym. Ed. 2008, 19, 1261-1278. [CrossRef]

40. Kim, I.; Viswanathan, K.; Kasi, G.; Sadeghi, K.; Thanakkasaranee, S.; Seo, J. Poly(Lactic Acid)/ZnO bionanocomposite films with positively charged $\mathrm{ZnO}$ as potential antimicrobial food packaging. Polymers 2019, 11, 1427-1443. [CrossRef]

41. Liu, Y.; Wang, X.; Yang, F.; Yang, X. Excellent antimicrobial properties of mesoporous anatase TiO2 and $\mathrm{Ag} / \mathrm{TiO} 2$ composite films. Microporous Mesoporous Mater. 2008, 114, 431-438. [CrossRef]

42. Akhavan, $\mathrm{O}$. Lasting antibacterial activities of $\mathrm{Ag}-\mathrm{TiO} 2 / \mathrm{Ag} / \mathrm{a}-\mathrm{TiO} 2$ nanocomposite thin film photocatalysts under solar light irradiation. J. Colloid Interface Sci. 2009, 336, 117-124. [CrossRef]

43. Joyce-Wöhrmann, R.M.; Münstedt, H. Determination of the silver ion release from polyurethanes enriched with silver. Infection 1999, 27, S46-S48. [CrossRef]

44. Jamuna-Thevi, K.; Bakar, S.A.; Ibrahim, S.; Shahab, N.; Toff, M.R.M. Quantification ofsilver ion release, in vitro cytotoxicity and antibacterial properties of nanostructured Ag doped $\mathrm{TiO} 2$ coatings on stainless steel deposited by RF magnetron sputtering. Vacuum 2011, 86, 235-241. [CrossRef]

45. Chim, H.; Hutmacher, D.W.; Chou, A.M.; Oliveira, A.L.; Reis, R.L.; Lim, T.C.; Schantz, J.T. A comparative analysis of scaffold material modifications for load-bearing applications in bone tissue engineering. Int. J. Oral. Maxillofac. Surg. 2006, 35, 928-934. [CrossRef]

46. Munteanu, B.S.; Aytac, Z.; Pricope, G.M.; Uyar, T.; Vasile, C. Polylactic acid (PLA)/Silver-NP/VitaminE bionanocomposite electrospun nanofibers with antibacterial and antioxidant activity. J. Nanopart. Res. 2014, 16, 2643. [CrossRef] 
47. Kim, E.S.; Kim, S.H.; Lee, C.H. Electrospinning of polylactide fibers containing silver nanoparticles. Macromol. Res. 2010, 18, 215-221. [CrossRef] 